\section{The Moving to Action Symposium Series: Engaging the Paradox of Childhood Obesity and Hunger}

\section{Abstract}

Attendees of Convergence of Childhood Obesity and Hunger: Moving to Action oneday symposium at Cabrini University in 2017 included employees from hospitals, higher education, and community organizations. The student attendees were from a variety of majors including biology, business, exercise science, and psychology. The agenda included keynote speakers, participant activities, networking, and an economical and nutritional based menu. A 10-item survey was sent to 118 participants after the event. Follow-up interviews were also executed. Forty-three people completed the survey (response rate of $36.4 \%$ ). Respondents were highly satisfied with the information shared and the organization of the event. They reported an increase in awareness of trends in childhood obesity and hunger, clarity of strategies to combat the problems and ability to identify community partners.

Keywords: Childhood obesity, Childhood hunger; Public health; Community engagement; University/Community collaboration; Assessment

\section{Hallion ME ${ }^{1}$ and Matthews TL $^{2 *}$}

\author{
Department of Health and Exercise \\ Science, Cabrini University, Radnor, PA, \\ USA \\ Department of Leadership and \\ Organization Development, Cabrini \\ University, Radnor, PA, USA
}

\section{*Corresponding author: Matthews TL ”tlm395@cabrini.edu \\ Department of Leadership and Organization Development, Cabrini University, Radnor, PA, USA.}

Citation: Hallion ME, Matthews TL (2019) The Moving to Action Symposium Series: Engaging the Paradox of Childhood Obesity and Hunger. J Child Obes Vol.4 No. 1:4.

\section{Introduction}

The prevalence of obesity in children and adolescents is greater than 18 percent and has increased substantially over the past 30 years [1]. The factors that contribute to the increase of childhood obesity rates are complex and include biological, environmental, social, cultural and behavioral influences [2-5]. Children who are overweight have increased risk of diabetes, cardiovascular disease, orthopedic disorders, depression and low self-esteem [6].

The concern pertaining to childhood nutrition is the increase in poor calorie consumption including fat, sugar and sodium with decrease intake of fruits and vegetables. Ironically, this dietary situation can also result when children are food insecure. Seventeen percent of households with children are estimated to be food insecure, nearly 13 million children [7]. Children who are hungry have higher hospitalization rates, slower recovery from illness and are susceptible to obesity [8].

Obesity and hunger can both be characterized as global health crises, yet they are widely thought to be mutually exclusive. Higher poverty, unemployment and decreased home ownership have resulted in more families facing food insecurity $[9,10]$. A surprising fact is that hunger and obesity can coexist in the same community, family or individual $[4,5]$. The greatest risk of obesity is for low-income women and children, resulting in a reduction in access to healthy food and opportunities for physical activity $[4,9]$.

Dr. Maria Elena Hallion, Associate Professor and Chair of Health and Exercise Science, Cabrini University interest in childhood obesity and food insecurity began when she completed a sabbatical at A.I. Dupont Hospital for Children's weight management clinic in 2011. Shortly after, the documentary A Place at the Table by Magnolia Pictures was released and the Let's Move campaign launched its comprehensive website bringing attention to the relationship between childhood obesity, health and socioeconomic factors [12]. Stuffed and Starved, revised and re-released in 2012, details how the global food system results in over one billion starving people while simultaneously more who are overweight. The Academy of Nutrition and Dietetics produced Nourish to flourish infographic depicting how food insecurity and obesity are linked [9]. These were instrumental in demonstrating the clear convergence of what once were thought of as polar opposites or a paradox, childhood obesity and hunger $[11,12]$. 
An outcome of Dr. Hallion's sabbatical was the creation and delivery of a social justice course offered as part of the social justice curriculum at Cabrini University called Engagement in the Common Good. Let's Feed Kids Well examines the complex factors of the rising childhood obesity rates which include access to affordable nutritious foods. In an effort to expand the audience, Dr. Hassink and Dr. Hallion created the Convergence of Childhood Obesity and Hunger symposium series. This article summarizes the symposium and presents the results from participant evaluation used to assess its effectiveness.

\section{Research Methodology}

\section{Description of convergence of childhood obesity and hunger: Moving to action}

In 2015, Convergence of Childhood Obesity and Hunger: A Forum for Response was held at Cabrini University. This was a one-day symposium where nearly 180 professionals, students and community organizers learned about the importance of connecting childhood obesity and hunger-two leading public health issues in the nation-in order to solve them both. The sponsors of the program included the Peggy and Leo Pierce Family Foundation, West Chester University, Eastern University, Mainline Health, Montgomery County Medical Society of PA, Exercise Science and Health Promotion Department, and Sodexo. Talks focused on several critical issues, including: childhood obesity, childhood nutrition, national food resources and food security, food waste and sustainability, and food policy. Speakers included: Dr. Sandra Hassink, President, American Academy of Pediatrics, Pediatrician, Nemours/Alfred I. duPont Hospital for Children in Wilmington, DE; Mary Pat Raimondi, Vice President, Strategic Policy and Partnerships Academy of Nutrition and Dietetics Foundation; Dr. Solomon Katz, Director of the Krogman Growth Center and Professor of Anthropology, University of Pennsylvania; Steven M. Finn, Co-Founder and Managing Partner, Response Ecology; and Eric Mitchell, Government Relations Director, Bread for the World.

The full-day workshop also included presentations from regional organizations, including the North Penn Community Health Foundation, the Health Promotion Council of Southeastern Pennsylvania, Chester County Food Bank, and Manna on Main Street. Lunch and interactive sessions provided opportunities for participants to engage with the speakers and learn more about community resources.

\section{Overall goals}

- To foster inter-professional collaboration regarding childhood obesity and hunger.

- To encourage undergraduate and graduate students from regional schools in the fields of Health, Education, Public Health, Social Work, Nutrition, Exercise Science, public policy that prepare them for work in either childhood obesity or hunger, to also consider the other issue.

\section{Objectives}

On February 17, 2017, Cabrini University hosted a second oneday symposium entitled Convergence of Childhood Obesity and Hunger: Moving to Action. This event provided attendees with collaborative discussions that helped them analyze trends within and links between childhood obesity and hunger and identify ways the community can help resolve these issues in their community. Sponsors of the program included: The Peggy and Leo Pierce Family Foundation, West Chester University, Mainline Health/Nemours, Montgomery County Health Alliance, Shoprite of Brookhaven, and Sodexo. This symposium was intended to provide the audience of service providers, educators, and leaders from local organizations, as well as undergraduate and graduate students in health, education, social work, public policy, and nutrition the opportunity to share ideas and identify community action opportunities on childhood obesity and hunger.

The agenda for the day once again incorporated several nationally-known keynote speakers, including returning speakers: Dr. Sandra Hassink and Eric Mitchell, along with Kim Fremont Fortunato, Director of Community Affairs, Campbell Soup Company and President, Campbell Soup Foundation, and Dr. Garrett Broad, Assistant Professor, Fordham University. The talks focused on the triple threat of obesity, food insecurity and hunger, ending hunger by 2030 , developing healthy communities, and food justice and community change. The activities for the day also included opportunities for the attendees to share ideas during collaborative discussions aimed at identifying community action opportunities, clarifying goals and strategies, identifying resources, and fostering inter-professional collaboration between those committed to combating childhood obesity and hunger.

Participants were instructed to complete various sections of program worksheets throughout the day to enable them to clarify their primary target community and its influencers, create goals for change, define actions steps and possible barriers to goals, and identify necessary resources. Attendees also participated in a networking portion of the program called Community Connections.

Meal planning aligned with the theme of the events by serving economical and nutritional items for breakfast and lunch which included oatmeal, salads made with in-season, locally grown fruits and vegetables, homemade vegetarian chili, brown rice and chicken thighs. The Food Recovery Network chapter of Cabrini University planned ahead to take all the usable leftovers from the event to a local shelter. This included eight pounds of apples, 45 pounds of prepared food including chicken, rice, vegetables, corn bread, and brownies. The symposium's target audience included service providers, teachers, and leaders from local organizations, and undergraduate and graduate students in health, education, social work, public policy, and nutrition. Continuing education credits were available for several professional bodies.

\section{There were four program objectives identified for the 2017 symposium. These included:}

- Objective 1: To share the current, documented national childhood obesity and hunger trends and clarify the linkages 
between the two problems.

- Objective 2: To foster inter-professional collaboration between those committed to combating childhood obesity and hunger.

- Objective 3: To assist attendees with identifying opportunities for community action including clarifying goals, strategy development and resource identification.

- Objective 4: To assist students, from various fields of study, to identify potential research, service and career opportunities that integrate both childhood obesity and hunger.

Accomplishing each of these objectives was considered as central to the success of the symposium, and more broadly to helping to advance efforts to reduce childhood obesity and hunger.

\section{Results}

A survey was designed based on evaluation surveys utilized for similar events by a colleague at another higher education institution. This survey was executed in the weeks following the event, utilizing the Survey Monkey data collection tool. Based upon certain survey results, it was then decided to add a semi-structured interview for selected participants to deepen understanding of aspects of the event, along with gathering additional contextual information.

One hundred thirty individuals participated in the event on the campus of Cabrini University in February 2017. All participants who provided an email address $(\mathrm{N}=118)$ were contacted two weeks after the event to complete a short survey designed to elicit opinions on the event, the speakers, and on the participant's self-perceptions related to their ability to engage in action related to childhood obesity and hunger. Forty-three people completed the survey, for a response rate of $36.4 \%$. (Tables 1-3) provide summary descriptive information from the survey (Table 1).

Approximately half of the participants who responded were affiliated with Cabrini University (as students or faculty Employed respondents work in a variety of sectors: $27 \%$ in Hospitals and $27 \%$ in Higher Education, $23 \%$ in Community Organizations, and $23 \%$ in other organizations. The students who participated were mostly undergraduates, divided rather evenly between sophomores, juniors and seniors. They were also from a variety of majors or programs, including biology, business management, exercise science and health promotion, leadership, and psychology (Table 2).

Majority of the respondents (58\%) who participated were equally interested in both childhood obesity and hunger, with just over $19 \%$ each interested primarily in either childhood obesity or hunger. As observed in Table 2, respondents overall reported very high levels of satisfaction with the organization of the event $(97.7 \%$ were satisfied or very satisfied). The respondents were also highly satisfied with the overall information provided by the speakers $(90.7 \%$ were satisfied or very satisfied) (Table 3-5), regarding their perceptions following attendance at the Convergence event, over $85 \%$ expressed agreement or strong
Table 1: Descriptive information for survey participants $(\mathrm{N}=43)$.

\begin{tabular}{|c|c|c|}
\hline Variable Information & Frequency & Percent \\
\hline Relationship to Cabrini University? \\
\hline Student & 16 & $40 \%$ \\
\hline Faculty & 5 & $12.50 \%$ \\
\hline Friend & 19 & $47.50 \%$ \\
\hline If employed, what sector do you work in? \\
\hline Hospital & 6 & $27.30 \%$ \\
\hline School (K-12) & 1 & $4.60 \%$ \\
\hline Higher Education & 6 & $27.30 \%$ \\
\hline Community organization & 5 & $22.70 \%$ \\
\hline Other & 4 & $18.20 \%$ \\
\hline If student, year in college? \\
\hline Sophomore & 6 & $37.50 \%$ \\
\hline Junior & 3 & $18.80 \%$ \\
\hline Senior & 5 & $31.30 \%$ \\
\hline Graduate Student & 2 & $12.50 \%$ \\
\hline Primary interest related to event? \\
\hline Childhood obesity & 5 & $19.20 \%$ \\
\hline Hunger & 5 & $19.20 \%$ \\
\hline Both are equally important & 15 & $57.70 \%$ \\
\hline Unsure/other & 1 & $3.90 \%$ \\
\hline
\end{tabular}

Table 2: Level of satisfaction expressed by participants following event $(\mathrm{N}=43)$.

\begin{tabular}{|c|c|c|}
\hline Variable Information & Frequency & Percent \\
\hline Satisfaction with speaker information \\
\hline Very satisfied & 24 & $55.80 \%$ \\
\hline Satisfied & 15 & $34.90 \%$ \\
\hline Neutral & 2 & $4.70 \%$ \\
\hline Dissatisfied & 2 & $4.70 \%$ \\
\hline Satisfaction with organization of event \\
\hline Very satisfied & 30 & $69.80 \%$ \\
\hline Satisfied & 12 & $27.90 \%$ \\
\hline Neutral & 1 & $2.30 \%$ \\
\hline
\end{tabular}

\section{Objective 2: Achieved}

It is vital for those committed to these issues to share resources, best practices, challenges and information. The portion of the event called Community Connections provided every attendee an opportunity to speak with representatives from eighteen local and regional organizations, including entities in health care, social services, higher education, and government. Participants and representatives were able to exchange contact information and discover opportunities for future collaboration. Also, during breaks and meals, attendees were able to dialogue with keynote speakers and program organizers.

The interview and survey results demonstrate the effectiveness of this portion of the agenda. Over $90 \%$ of survey respondents noted an ability to identify linkages, partners, the target community and community influencers as a result of the symposium, and several interview respondents focused particular attention on how the event allowed them to both strengthen existing connections and make new ones. 
Table 3: Frequencies and percentages for respondent level of agreement of various statements following the convergence event ( $N=43$ ).

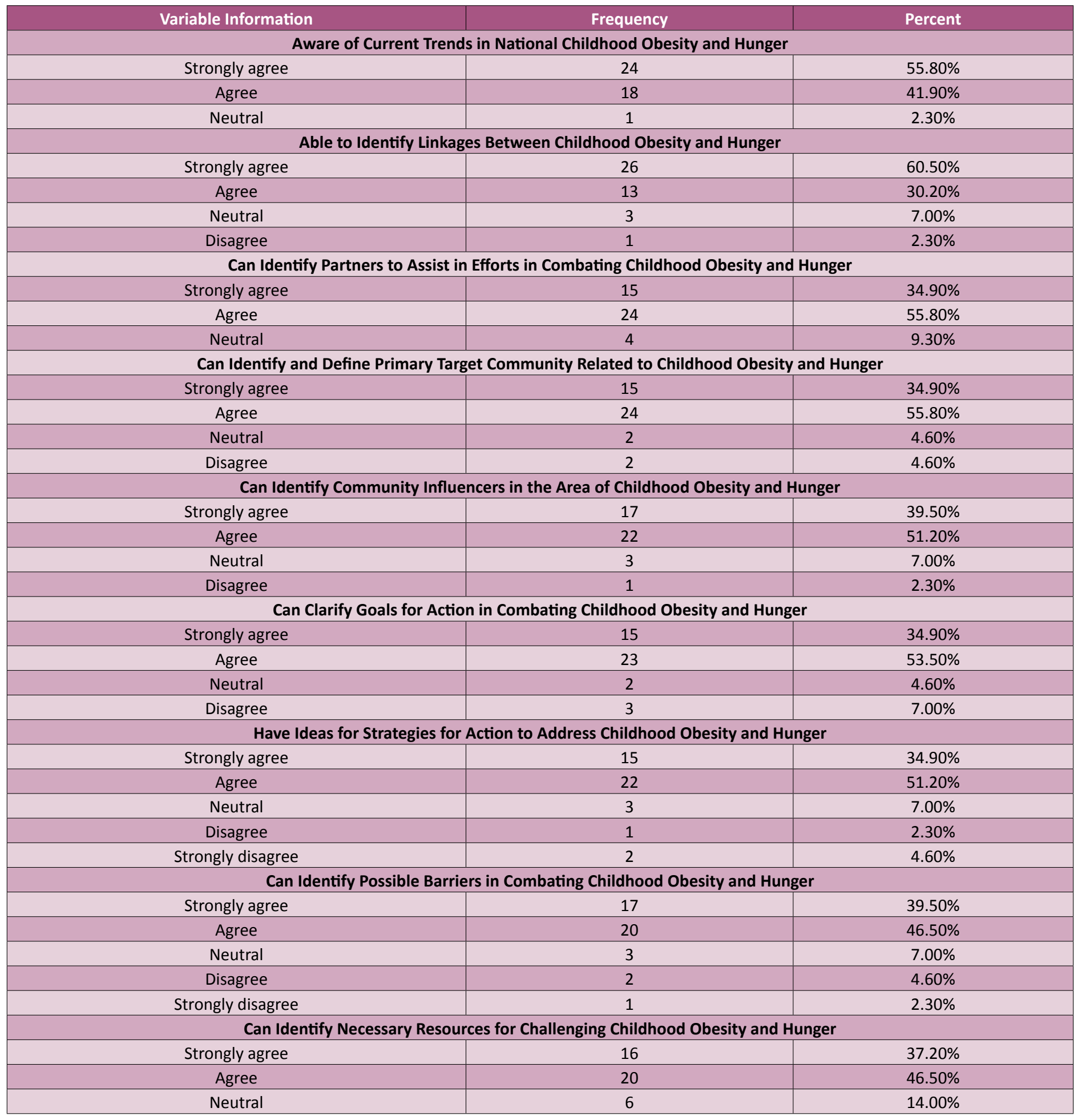

\section{Objective 3: Achieved}

This year's program was enhanced to include participant worksheets to achieve this objective. Following the Community Connections segment of the day, the participants utilized these worksheets to help move towards action, based on the opportunities discovered and the connections they just made. Attendees were prompted and given time to complete the various elements which included identifying their target community and its influencers, setting preliminary goals, action steps, possible barriers and necessary resources to creating change. Additionally, Dr. Garrett Broad and Kim Fremont Fortunato both shared extensive information about community collaboration, thus contributing significantly to the achievement of this objective.

The results of the interview and survey again demonstrate the effectiveness of this portion of the agenda. Over $85 \%$ of respondents expressed agreement or strong agreement with the more action-oriented statement prompts related to clarifying goals for action, strategies for action, possible barriers and 
Table 4: Community and faculty participant comments on program.

\section{Participant comments on program}

- One individual appreciated the opportunity to strengthen the relationship they have with their local hospital due to the community connections portion of the day.

- A representative from a local food pantry was able to establish a relationship with another food pantry in Delaware.

- A local educator was able to develop a deeper relationship with a local food pantry whom they had already been partners with previously.

- A university professor was pleased to make connections with others doing work around college student hunger.

- One respondent expressed appreciation for the speakers and information, and added: "my favorite part was networking... I even connected with people and companies from my home town!

Table 5: Student participant comments on program opportunities.

\section{Participant comments on program opportunities}

- "I have an increased interest in pediatric childhood obesity. Previously, I worked with (a local food pantry) and their healthy snacks when employed at the (local civic organization) for about 4 years."

- $\quad$ Another student credited the symposium for getting the idea for their senior internship working with children at a local hospital.

necessary resources. Additionally, several responses in the interviews indicated steps towards action that respondents were going to take based on the symposium.

\section{Objective 4: Partially Achieved}

Attendees who participated in the event were exposed to community service and career opportunities. However, it is not evident that students who attended were exposed to research opportunities. Based on this, the program planners sought to develop more research opportunities, particularly at the graduate student level, for the 2019 symposium.

The overarching goals of all the programs have remained the same and have been achieved. To be clear, these programs are not offering direct services or measuring how efforts emerging from the symposia series may be resulting in lowered rates of the of childhood obesity or hunger However, it is part of the program expectations that as more people become better informed and connected with others who work on these issues in our region it can only help to support more direct efforts to address these problems over time.

Results of this impact study were used to plan and deliver the third symposium in this series that was held on February 22, 2019 at West Chester University in West Chester, PA, and entitled the Convergence of Childhood Obesity and Hunger: Taking Action. Keynote speakers included Dr. Sandra Hassink, Director of the American Academy of Pediatrics Institute for Healthy Childhood Weight; Atif Bostic, Executive Director, Uplift Solutions and Christine Melendez Ashley, Deputy Director, Bread for the World. The day included Community Connections networking a healthy, economically planned menu and a new element, breakout sessions with one focused on research opportunities for participants.

As this event connects scholarship and practice, it is imperative to ensure that both are sufficiently emphasized, and the first two symposia focused largely on opportunities for practice for the participants. The primary scholarly focus of the 2015 and 2017 symposia came from the content delivered to the participants by the keynote speakers and other presenters. The 2019 symposium attempted to expand opportunities for students to present information on activities designed to address the convergence of obesity and hunger across a wide spectrum of disciplines and approaches.

\section{Limitations}

As with any study, there are limitations associated with this project. First, this project represents a post-hoc effort to more thoroughly analyze the effectiveness of this one day symposium. However, given that this is an ongoing symposium series! Focused on two chronic public health problems, it seems that the importance of continuous improvement should override this concern. Second, the small sample size associated with the survey inhibited the ability to analyze different impacts across groups, such as students and professionals.

\section{Conclusion}

Symposia such as those described here have a great deal of potential to bring together different actors around important issues. Ongoing assessment of their effectiveness and impact is important to ensuring their success, particularly in an age of limited resources. Future research should continue to examine these sorts of activities, particularly to determine if they promote short and/or longer-term changes in knowledge, attitudes and actions related to preventing or reducing childhood obesity and hunger.

\section{Acknowledgements}

The authors would like to thank Marissa Christensen, Savannah Walls, the event sponsors, and the Cabrini University Wolfington Center for their support of this project.

\section{Funding}

This work was supported by Cabrini University's Provost Office through the Buzzallino Family Award.

\section{Conflict of Interest}

The authors have no conflict of interests to disclose. 


\section{References}

1. Centers for Disease Control and Prevention (2017) Overweight and obesity: Childhood obesity facts.

2. Caprio S, Daniels SR, Drewnowski A, Kaufman FR, Palinkas LA, et al. (2008) Influence of race, ethnicity, and culture on childhood obesity: implications for prevention and treatment. Diabetes care 31: 22112221.

3. Harrison K, Bost KK, McBride BA, Donovan SM, Grigsby-Toussaint DS, et al. (2011) Toward a developmental conceptualization of contributors to overweight and obesity and children: the six-Cs Model. Child Dev Perspect 5: 50-58.

4. Relationship between poverty and obesity (2018) Food Research and Action Center.

5. Healthy Children, Healthy Weight (2018) Robert Wood Johnson Foundation.
6. Waters E, Swinburn B, Seidell J, Uauy R (2010) Preventing childhood obesity: Evidence policy and practice. Somerset, NJ: John Wiley and Sons, NY, USA.

7. Food Insecurity and Poverty in the United States (2018) Findings from the USDA and U.S. Census Bureau: Feeding America.

8. American Academy of Pediatrics (2015) New AAP Report Targets Lack of Adequate Food as Ongoing Health Risk to U.S. Children.

9. Benko B (2015) Nourish to flourish. Academy of nutrition and dietetics.

10. Johnson Askew W, McDowell M, Fisher R (2011) Hunger and its impact on children: Where do we go from here? J Hunger Environ Nutr 6: 383-397.

11. Patel R (2012) Stuffed and Starved: The hidden battle for the world food system. NY, Melville House, USA.

12. Jacobson K, Silverbush L (2012) A place at the table. Magnolia Pictures. 